\title{
Restoration of a dystrophic lake: the case of efoulan lake in yaounde cameroon
}

\begin{abstract}
Nowadays, the preoccupation for environment is increasing. This awareness is a realistic and pragmatic choice owing to numerous negative impacts of the nonenvironmental friendly technologies. The restorations of the dystrophic Efoulan Lake will pursuit this objective. Solutions for that restoration will be dry dredging combine with the sanitation of the River NTSOMO which is the affluent of the lake as well as the implication of politics to help people to adopt green facility such as decentralised systems.
\end{abstract}

Keywords: lake, restoration, dry dredging, decentralised system
Volume 2 Issue I - 2018

\author{
Abanda Well Victorien Bienvenu,' Gideon A \\ Ajeagah, ${ }^{2}$ George E Nkeng' \\ 'National Advanced School of Public Works, Cameroon \\ ${ }^{2}$ University of Yaounde I, Cameroon
}

Correspondence: Victorien B Abanda, National Advanced School of Public Works, Yaounde, Cameroon,

Email victorien_abanda@yahoo.fr

Received: December 13, 2017 | Published: January II, 2018

\section{Introduction}

Lakes are inland waters with a low flow rate. This property may increase their vulnerability particularly when there are subjected to pollution. The pollution of lakes is very usual, in lower income countries where there is a scarcity of sanitation facilities, poor culture of environmental protection and sometime a weak legislative framework. Once the lake is polluted, numerous compounds of the environment are affected. The effect of the lakes pollution is multisectoral: economical, political, social and environmental. Thus, the remediation of polluted lakes is a necessary and vital. One well known manifestation of that pollution is eutrophication which is the degradation of water quality due to an excess of algae. Yaoundé which is the political capital of Cameroon has numbers of its lacustrine media in eutrophic state. ${ }^{1,2}$ This situation hinders its own development since lakes sustain food for people thus contribute to fight against hungry and criminality. Furthermore, lakes provide work for fishermen and promote touristic activities. All these assets will contribute to increase the Gross Development Product (GDP) of the country.

\section{Methodology}

\section{Presentation of Efoulan Lake}

Efoulan Lake is located in Yaoundé in the quarter called "Efoulan". This lake is reduced to a small river called NTSOMO which cross all the quarter. Macrophytes occupy a large surface of this lake such that animals come to feed themselves there. Habitations in this zone is highly densified and constructed most of the time spontaneously. The economic activity closed to this lake is dynamic and characterised by many shops. Furthermore, there is a waste collection point which faces the lake. The following Figure 1 gives a panoramic view of the lake and its environment. The flow rate in Efoulan Lake is strongly influenced by climate variability which takes place in Yaoundé. Indeed, from November to May, the flow rate is low because it is the dry season. Meanwhile, from June to October, the flow rate is very high and attains its peak in October which is the rainiest month of the year. Furthermore, this lake frequently receives household wastes. The geometric characteristics of Efoulan Lake are summarised in Table 1. These characteristics are: length $(\mathrm{L})$, perimeter $(\mathrm{P})$, area $(\mathrm{A})$, drainage density $(d=L / A)$ shape coefficient $(F=P / 2 \sqrt{\pi S})$ and the slope is expressed as $i_{m}=1 / S \sum_{i} L_{i} \Delta Z_{i}$ : where $\mathrm{i}$ is the interval between two level points and $Z$ is the level. According to this, the lake has a gathered shape since $F \approx 1$. An analysis of the mean slope and the drainage density shows that this lake does not easily evacuate pollution. This has certainly contributed to increase its eutrophication. Description of the methodology used to perform chemical and biological characterisation of the lake. In this part, we record the methodology used by Ageagah et al. ${ }^{3}$ to set the ecological evaluation of Efoulan Lake. To correctly analyse the quality of Efoulan Lake, its water was sampled in an adiabatic container (to avoid interaction with environment which can initiates reactions and biases results). The latter was then sent in a laboratory for further analysis. The aim of laboratory analysis was to determine oxygen, nitrogen, phosphorous and carbon dioxide concentration. Nitrogen and phosphorous were analysed through spectrometric analysis while carbon dioxide and Dissolved Oxygen were analysed using APHA et al. ${ }^{4}$ methodology respectively. Macroinvertebrates were sampled using net and Moisan ${ }^{6}$ methodology.

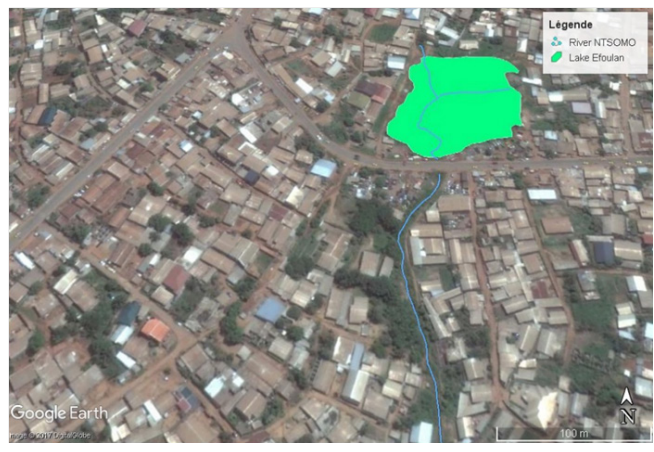

Figure I Overview of Efoulan Lake.

Table I Characteristics of Efoulan Lake

\begin{tabular}{lll}
\hline Parameters & Units & Values \\
\hline Length & $\mathrm{m}$ & $\mathrm{I} 19.58$ \\
Perimeter & $\mathrm{m}$ & 450.16 \\
Area & $\mathrm{m}^{2}$ & 12135 \\
Drainage density & $\mathrm{m}^{-1}$ & 0.00985 \\
Shape coefficient & $\mathrm{m}^{-1}$ & 1.153 \\
Slope & & 0.0288
\end{tabular}




\section{Restoration methodology}

Many methods are used in lake restoration: physical, biological, chemical and mechanical. Each of these methods are adapted for a particular context which can be social or economic. The success of a restoration action will depend on the mobilization of all the stakeholders which can impact the target ecosystem. The physical methodology only exploits the capability of water to manage pollution itself (Figure 2). This is achieved by avoiding contact between the tributaries and lake or promoting contact between them. Water diversion is a good illustration of the first case while water dilution can easily illustrate the second one. Chemical methods are operated though insertion of substances inside the lake in order to enable coagulation and flocculation of pollutants as well as the destruction of invasive plants like macrophytes. Coagulating and flocculating agents such as iron III chloride $\left(\mathrm{FeCl}_{3}\right)$ or copper II sulphate $\left(\mathrm{CuSO}_{4}\right)$ are used to remove organic matter but also phosphate owing to coprecipitation. Thus, while they precipitate, they bind phosphate particles and settle with them in the bottom of the lake. The removal of invasive macrophytes from lakes can be achieved using herbicides such as 2,4-D, diquat, endothall, copper sulphate and glyphosate. ${ }^{6}$ Meanwhile, numbers of chemical substances are very unsafe for the biota since they are persistent ${ }^{1}$ for this reason natural organic flocculants like starch are used despite their lower efficiency. The restoration of a lake using mechanical method is achieved through dredging which can be dry or wet. Dry dredging is suitable in the case of sediment desiccation; wet and hydraulic dredging is used without the necessity to remove water. They can be operated as seen in Figure 3 above. During wet dredging, gases are released from sediments. Their unpleasant odour pollutes the air; thus, they are not adequate for dense environment. Hydraulic dredging is a quiet system and is suitable for the extraction of fine sediments. Meanwhile, it is adapted to deep lakes and its operating cost is expensive. Biological method is the remediation of lakes using living things. One of the main purpose of this method is to promote plankton grazing. This can be achieved by cancelling planktivorous fishes from the water column through man selection or the introduction of some piscivorous species which prey them. The introduction of plants with allelopathic substances can also be interesting since they will eliminate invasive ones. Meanwhile, nontarget plants can also be affected by this action. Thus, we should be very careful when we use this method.

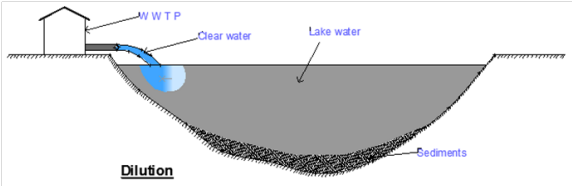

A

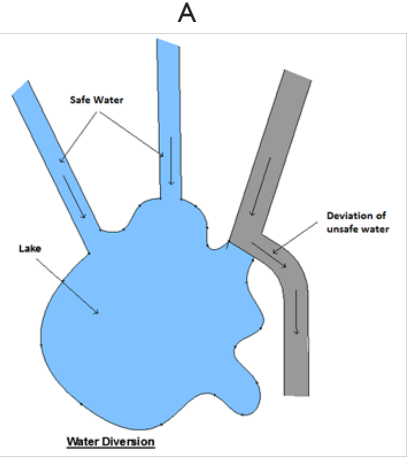

B

Figure 2 Overview of physical methods, water dilution (A) and water diversion (B); Source.

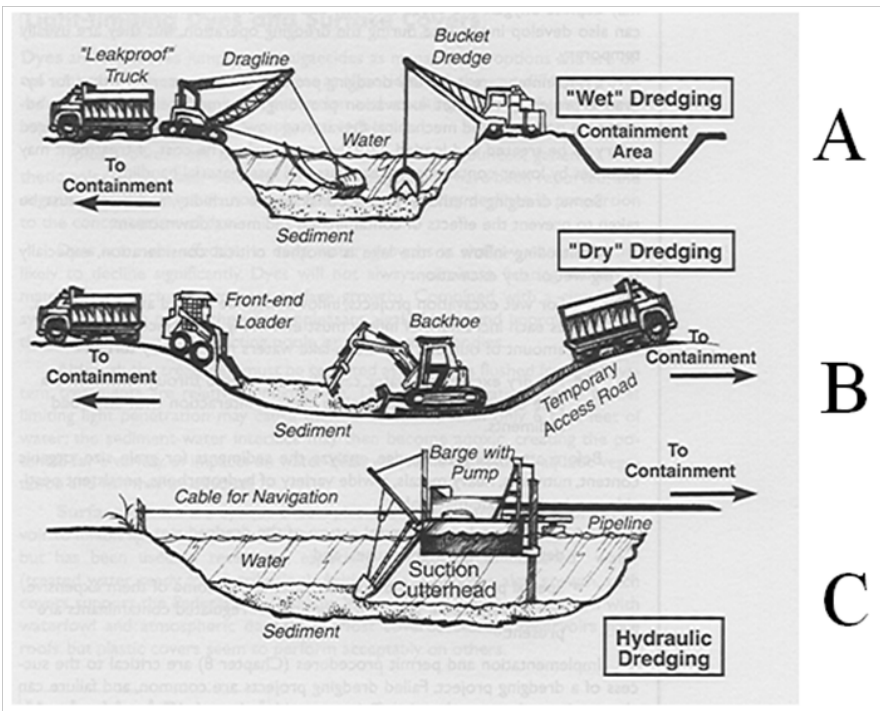

Figure 3 Mechanical methods, A. Wet dredging; B. Dry dredging; and C. Hydraulic dredging; source. ${ }^{13}$

\section{Results and discussion}

The physico chemical characterisation of Efoulan Lake realised by Ajeagah et al. ${ }^{3}$ revealed that Dissolved Oxygen (DO) concentration was $0.08 \mathrm{mg} / \mathrm{L}$ and the oxygen saturation was less than $50 \%$. This is very illustrative of the state of pollution encounter in this lake. Moreover, the value of nitrate and $\mathrm{CO}_{2}$ was $34 \mathrm{mg} / \mathrm{L}$ and 40.5 $\mathrm{mg} / \mathrm{L}$ respectively. While the concentration of orthophosphate was $40 \mathrm{mg} / \mathrm{L}$. All these concentrations are highly below their standard threshold limit as proposed by Galvez-Cloutier et al. ${ }^{7}$ The analysis of macroinvertebrates caught has shown the presence of Coleoptera, Ephemeroptera, Hemiptera, Basommatophora, Rhynchobdellida, Odona, Mesogastropoda and Diptera. The latter was the most abundant and represented $94.65 \%$ of the total macroinvertebrate sampled. This confirms the dystrophic state of the lake (Figure 4). The restoration of Efoulan Lake will consist to remove dry sediments through dry dredging (Figure 3B). The enlargement of the lake surface will cause water to expend naturally and fill all the lake. The removed sediments should not be landfill since they can be used by people to construct embankment for their house or to maintain unpaved roads. As proved by analysis, the quality of the river NTSOMO is seriously affected thus its sanitation will be primordial for the restoration of the lake. Since that river receives wastes from household and sceptic tanks, the use of twin pit VIP latrine (Figure 5) is highly promoted for spontaneous habitations. ${ }^{1}$ According to EAWAG, ${ }^{8}$ the adoption of twin pit VIP latrine will have many advantages:

a. Easy excavation of humus which can be used as natural fertiliser.

b. Great reduction of pathogens.

c. Use of faecal material as soil conditioner.

d. Maintenance is possible using local materials.

Simultaneously, their main drawbacks are:

a. Manual removal of humus.

b. Possible contamination of ground water.

c. The operating cost is high. 


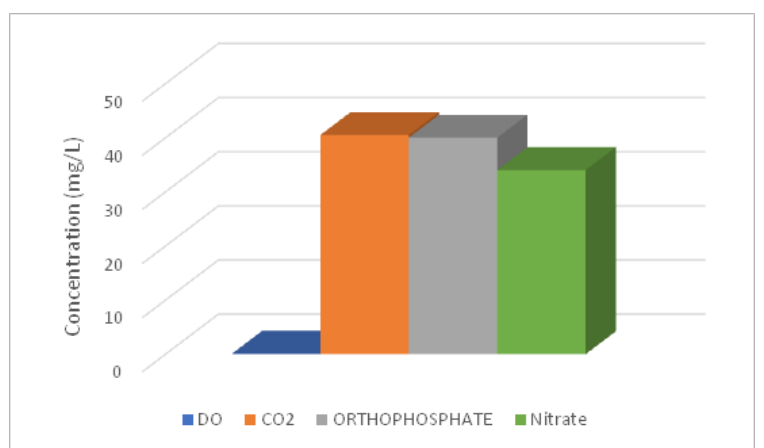

Figure 4 Results from chemical analysis of Efoulan Lake.

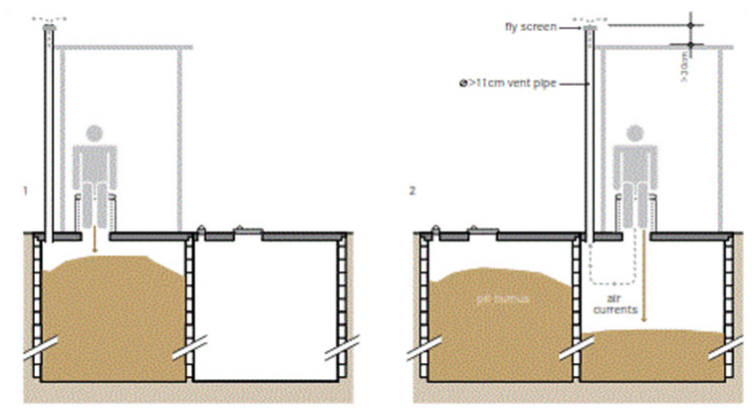

Figure 5 Twin pit VIP latrine; source. ${ }^{8}$

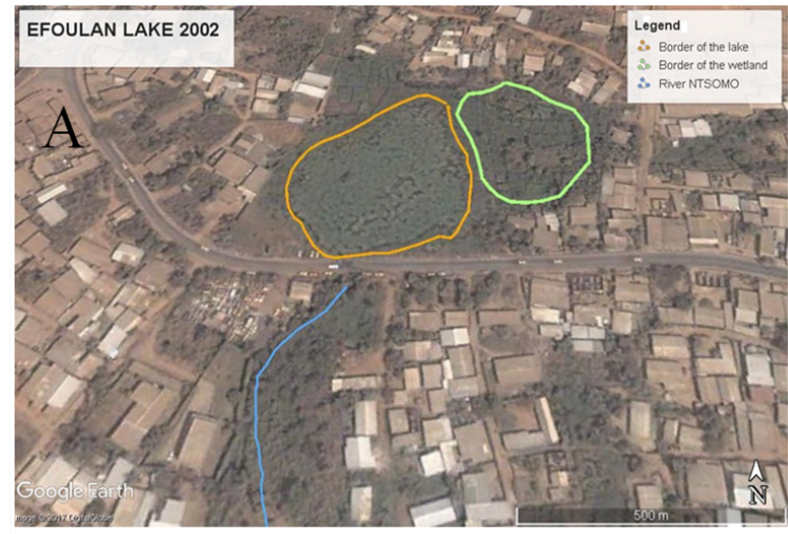

Figure 6 Visualization of the Efoulan Lake in A. 2002; and B. 2017.

\section{Conclusion}

The lake Efoulan is dystrophic as clearly shown by the chemical and biological analysis realized by Ajeagah et al. ${ }^{3}$ Its remediation which will consist to dry dredging and the promotion of decentralised system will greatly contribute to its restoration. The role of politics will also be important since it can greatly motivate people to experiment green technologies. Nowadays, the "green" is fashionable because environmental preoccupations increase and attract investors and tourists. States organise conferences COP21, 22, 23 and more recently the "one planet summit" organised by the French president Emmanuel Macron to motivate governments to opt for green technologies. At the end of that conference, many organisation and companies like the World Bank and AXA promised to no longer finance projects which deal with climate change. The latter contribute to the progressive disappearance of inlands water and an increase of water crisis which enhance lakes eutrophication. ${ }^{12}$ The organization of these types of
As mentioned above, the setup of twin pit VIP latrine is highly expensive especially for lower income countries like Cameroon. Its implementation will require 500000 FCFA which is not affordable by many people of the place. Thus, a possible solution is that the local municipality or the government subsidise it. These actions will impulse even at national level the adoption of environmental friendly technologies. The treatment of the black water is also a challenge because it has many sources which are conveyed in the lake. This water is rich in heavy metals and contains a high organic load. The implementation of decentralised systems such as wetlands ${ }^{9}$ can greatly contribute to solve this problem. The best solution will be the construction of a centralised system but it is not a realistic solution and even if it is setup, its cost will be highly expensive. Thus, Yaoundé city council can just opt for incentive measures such as the suppression of the tax for waste removal. ${ }^{10}$ The government of Cameroon must also invest in the formation of environmental engineer which will implement this kind of technology and sufficiently promote it. The anarchic occupation of wetland is greatly detrimental to lake water quality owing to the bio depurative property of wetlands. As clearly seen in Figure 6, the colonisation of a part of the wetland has increased the eutrophication of the lake. This result is in perfect accordance with Olajuyigbe et al. ${ }^{11}$ who evaluate the impact of the urbanization on wetland in AKURE using GIS. We see the presence of habitations in the wetland zone. These habitations without any respect of the planification made by the city council of Yaounde increase the vulnerability of lake and lead to eutrophication.

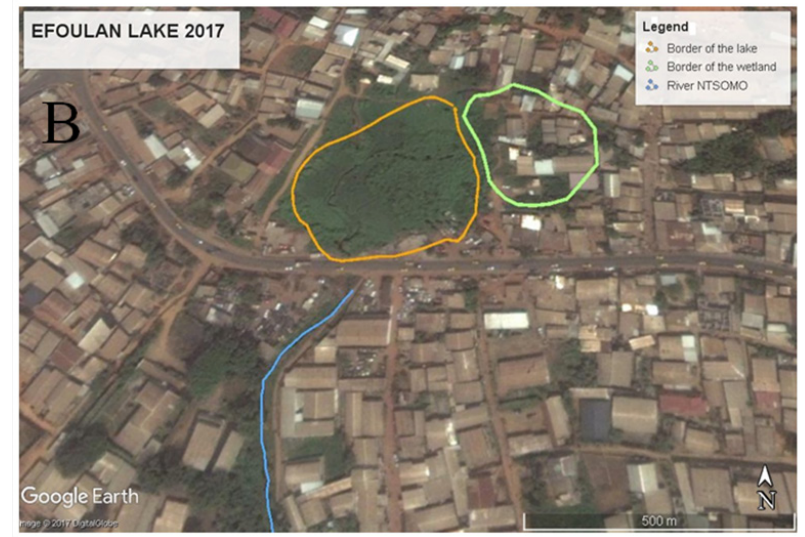

conference is important since they contribute to the safeguard of lacustrine media all over the world. The government of Cameroon which will organise the African Cup of Nation (CAN) in 2019 fixed its emergence in 2035. Its attention for the protection of the environment is visible through the fighting against desertification, flooding, watershed pollution, etc. This clearly confirms the motivation for this state to face environmental problems. Furthermore, it traduces a reality: the emergency of Cameroon should not be evaluated only by political, social and economical development; but, it will be also through ecological development. Thus, Cameroon is in the good path and must continue to restore its watershed in order to totally follow the road of sustainable development. ${ }^{13}$

\section{Acknowledgments}

I would like to express my sincere gratitude to Pr Gideon Ageagah for accompanying my first steps in research. I would like to thank the 
partnership between the National Advanced School and Public Works of Yaoundé and the university of Padova in Italy for the high quality of the formation that I received during my Master In Engineering studies. Finally, I would like to thank my family for the inexhaustible love for me.

\section{Conflict of interest}

I undersigned ABANDA WELL Victorien Bienvenu certify on the honour that I have no affiliations with any financial interest and non-financial interest in the subject matter, material and results of this manuscript.

\section{References}

1. Abanda Well Victorien Bienvenu. How to remediate eutrophic lakes? Lambert Academic Publishing (LAP), Germany; 2017.

2. Zebaze TSH. Zooplancton et eutrophisation d'un lac en zone tropicale: Structure de la communauté zooplanctonique et eutrophisation du Lac Municipal de Yaoundé (Afrique Centrale). Univ Europeenne. 2011. p. $1-4$.

3. Ajeagah GA, Kaounodji S, Abanda WV, et al. Bio-environmental and ecological evaluation of lenthic water bodies in tropical Africa: case of the lakes of Yaoundé (CAMEROUN). Proceedings of Expert Workshop Water Security, Ethiopia. 2017. p. 1-57.

4. APHA, AWWA, WEF, et al. Standard methods for the examination of water and wastewater. APHA-AWWA-WEF USA, 2005. p. 1-541.

5. Moisan J. Guide d'identification des principaux Macroinvertébrés benthiques d'eau douce du Québec - surveillance volontaire des cours peu profonds (2010). Ministère du Développement Durable, de l'Environnement et des Parcs, Canada; 2010. p. 1-89.
6. Cooke G, Welch E, Peterson S, et al. Restoration and Management of lakes and reservoirs. CRC Press, UK; 2005. p. 1-168.

7. Galvez CR, Ize S, Arsenault S. La détérioration des plans d'eau: Manifestations et moyens de lutte contre l'eutrophisation. VECTEUR environnement. 2002;35(6):18-37.

8. EAWAG. Compendium of sanitation systems and technologies. EAWAG Aquatic research, UK; 2014.

9. Kadlec RH, Wallace SD. Treatment Wetlands. CRC Press. USA; 2009. p. 1-366.

10. Ajeagah GA. Eutrophication capacity and environmental sanitation of tropical aquatic ecosystems in Yaounde (Cameroon): hydrological physicochemical and parasitological potentialities. $5^{\text {th }}$ international conference on the advancement of science and technology (ICAST 2017), Cameroon. 2017. p. 1-124.

11. Olajuyigbe AE, Suleiman AAA, Olusola OP, et al. Assessment of urban land use and environmental sensitive area degradation in AKURE, Nigeria using remote sensing and GIS techniques. European Scientific Journal. 2015;11(9).

12. Ajeagah GA. Water as a wapon of international confrontations. Harmattan, Cameroon. 2017. p. 1-220.

13. Holdren JT. Managing Lake and Reservoirs. In: Wagner K, editors. Management Techniques within the Lake or Reservoir, USA; 2001. 